\title{
Bandwidth Enhancement of U Shape Notched Microstrip Patch Antenna for Low Frequency Band
}

\author{
Surendra Kumar Gupta ${ }^{1}$, D.K. Srivastava ${ }^{2}$, Ravi Kant Prasad ${ }^{3}$ \\ P.G. Student, Department of Electronics and Communication Engineering, B.I.E.T. Jhansi, U.P., India ${ }^{1}$ \\ Associate Professor, Department of Electronics and Communication Engineering, B.I.E.T. Jhansi, U.P., India ${ }^{2}$ \\ Research Scholar, Department of Electronics and Communication Engineering, B.I.E.T. Jhansi, U.P., India ${ }^{3}$
}

\begin{abstract}
In this research paper, microstrip patch antenna with U-shape notched is analysed. Proposed antenna is suitable for band $(1.965-2.508 \mathrm{GHz})$ for frequency band. The proposed antenna meet the required impedance bandwidth is $24.279 \%$. The dimension of proposed antenna is $\left(29.5 \times 38.0 \times 1.6 \mathrm{~mm}^{3}\right)$. This antenna exhibits bandwidth at $2.367 \mathrm{GHz}$ and Gain is $4.01543 \mathrm{dBi}$. The archived band can be optimized by change parameter of $\mathrm{U}$ Shape notched microstrip patch antenna. The variation in the design structure from $U$ shaped antenna is notching in the structure and varying the width of slot. The proposed antenna by introduces notching in the rectangular $\mathrm{U}$ shaped radiating patch, is suitable for Wireless application which works around frequency $2.4 \mathrm{GHz}$ and its VSWR is around 1.237 .
\end{abstract}

Keywords: Slotted Microstrip patch antenna, Feed-line, Return loss, Radiation pattern.

\section{INTRODUCTION}

Wireless communication devices mobility has increased the demand for compact and low profile antennas. The frequency range of proposed antenna is $(1.965-2.508 \mathrm{GHz})$ used for wireless Communication system which operated at $2.4 \mathrm{GHz}$ resonant frequency. In the proposed antenna the patch is designed in U-shaped for low frequency bandapplication realized by notching in the proposed antenna [1]. It may be used as indoor WLAN antenna application and is small enough that it will be compatible into any environment. To generate band for $2.4 \mathrm{GHz}$ WLAN operation, a compact U- shaped antenna is designed whose top and bottom length and width of the patch antenna (29.50 $\left.\times 38.00 \times 1.6 \mathrm{~mm}^{3}\right)$ and length and width of the ground of the antenna is $\left(39.50 \times 48.00 \times 1.6 \mathrm{~mm}^{3}\right)$. Patch antennas and planar antennas are proposed for cellular and WLAN applications [2]. The antenna dielectric subtracts FR4 epoxy of thickness of $1.6 \mathrm{~mm}$ and dielectric constant of 4.4 is used because it is cheap and easily available. The antenna is driven by a $50 \Omega$ microstrip line. In this paper design of single band of U-shaped microstrip patch antenna is designed that cover frequency band $(1.965-2.508 \mathrm{GHz})$ at $2.367 \mathrm{GHz}$ resonant frequency which can be well used for $2.4 \mathrm{GHz}$ frequency band applications. The directivity and gain of the antenna is satisfactory for wireless communication. Shifting in the resonant frequency is done by varying the parameters of the antenna. The VSWR of the antenna is around 1.237 which indicates the impedance matching of the proposed antenna is as per requirement [3]. The VSWR of proposed antenna is very important for used communication purpose. The advantages of the proposed U-shaped antenna are: easy configuration, good VSWR, good efficiency and good radiation pattern [4-7]. The proposed antenna used parameters of U-shape notched in the rectangular antenna isanalysed to adjust each of the operating bands; due to this the proposed antenna design can be used for other wireless band [8-11].

\section{GEOMETRY OF THE PROPOSED ANTENNA}

Table 1: Antenna Design Specifications

\begin{tabular}{|l|l|l|}
\hline S.No. & \multicolumn{1}{|c|}{ Antenna Parameter } & \multicolumn{1}{c|}{ Values } \\
\hline 1 & Resonant Frequency $\left(\mathrm{f}_{\mathrm{r}}\right)$ & $2.4 \mathrm{GHz}$ \\
\hline 2 & Substrate thickness $(\mathrm{h})$ & $1.6 \mathrm{~mm}$ \\
\hline 3 & Dielectric constant $\left(\varepsilon_{\mathrm{r}}\right)$ & 4.4 \\
\hline 4 & Loss tangent $(\tan \delta)$ & 0.0013 \\
\hline
\end{tabular}

For calculation of dimension several parameter such as resonant frequency $\left(f_{r}\right)$, substrate thickness $(h)$, loss tangent (tan 
$\delta$ ), and dielectric constant $\left(\varepsilon_{\mathrm{r}}\right)$, and $50 \Omega$ Microstrip line is used as feed into patch are required. The antenna specifications that are required are given in Table 1.

\section{III.PROCEDURE FOR ANTENNA DESIGNING}

In the designing of proposed antenna firstly design a rectangular patch with calculated dimension of patch and ground plane and design a U-shape on the patch. Then notching is introduced. U-shaped design has been modified by varying the thickness and position within the patch and introducing the notching with the variable length and width and these steps is performed stepwise. By following this procedure the bandwidth has been enhanced and resonant peak shifted towards lower frequency side. Dimensional parameters of proposed antenna are listedin Table 2.

Table 2: Calculated Antenna Dimensions

\begin{tabular}{|l|l|l|}
\hline S.No. & Antenna Dimension & Values $(\mathbf{m m})$ \\
\hline 1. & Ground Length $\left(\mathrm{L}_{\mathrm{g}}\right)$ & 39.50 \\
\hline 2. & Ground Width $\left(\mathrm{W}_{\mathrm{g}}\right)$ & 48.00 \\
\hline 3. & Patch Length $\left(\mathrm{L}_{\mathrm{p}}\right)$ & 29.50 \\
\hline 4. & Patch Width $\left(\mathrm{W}_{\mathrm{p}}\right)$ & 38.00 \\
\hline 5. & $\mathrm{~W}_{\mathrm{f}}$ & 05.00 \\
\hline 6. & $\mathrm{a}$ & 17.50 \\
\hline 7. & $\mathrm{~b}$ & 20.00 \\
\hline 8. & $\mathrm{c}$ & 03.00 \\
\hline 9. & $\mathrm{~d}$ & 09.00 \\
\hline
\end{tabular}

\section{IV.SIMULATION AND DISCUSSION}

The performance of proposed microstrip patch antenna is analysed by antenna designing software like IE3D simulation software tool at select resonant frequency of $2.4 \mathrm{GHz}$. A $50 \Omega$ microstrip line feed is inserted at the middle of length of the patch antenna and the design of calculated U-shaped coupled microstrip patch antenna is shown in Fig.1.

Simulation result of return loss is plotted for the range of frequency $1 \mathrm{GHz}$ to $3 \mathrm{GHz}$ and the curve crosses the -10dB as shown in Fig.2.It is calculated that the fractional bandwidth of proposed antenna is $24.279 \%$ which lies between 1.965 $\mathrm{GHz}$ to $2.6508 \mathrm{GHz}$ band and Return loss is $-19.49 \mathrm{~dB}$ at resonance frequency $2.367 \mathrm{GHz}$ has been obtained.

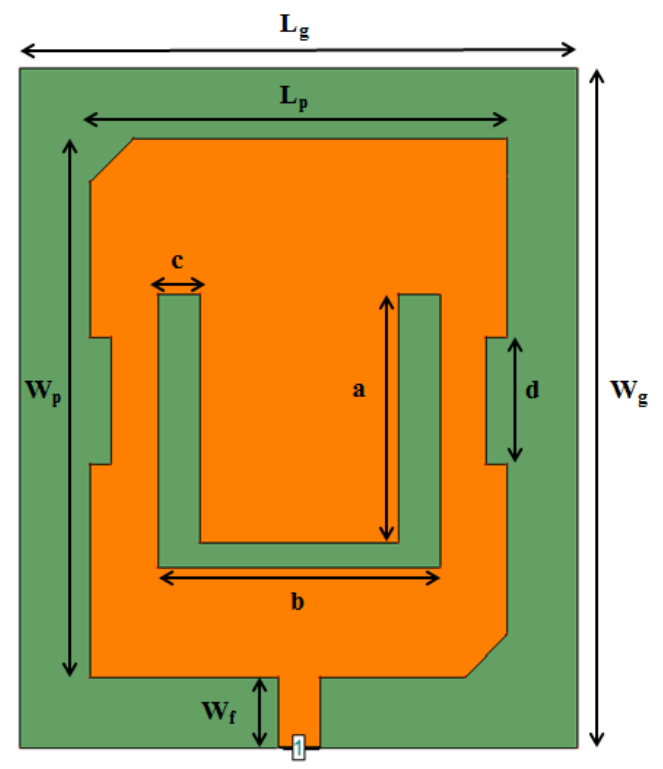

Fig.1 Geometry and dimension of the proposed Antenna

It is also observed that operating resonance frequency $2.367 \mathrm{GHz}$ shows close agreement with designed resonance frequency $2.4 \mathrm{GHz}$, above Result is the optimized result which is obtained by performing the different variation in the antenna parameter which is discussed below stepwise: 


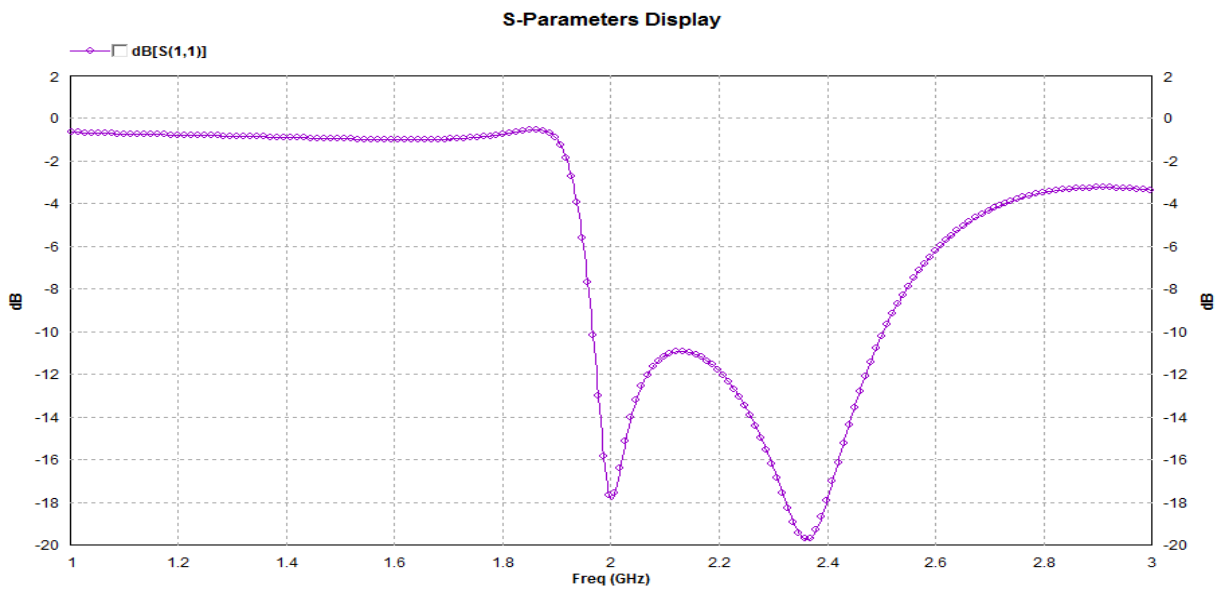

Fig.2 Simulation result of return loss

\section{A. Effect of Triangular Notch}

As the U-slotted patch antenna is optimized, it is necessary to improve the various characterized of the antenna by introducing the different types of notching in the antenna design. There aretwotype of notching is introduced in the design: Triangular and Rectangular. First of all onlyrectangularpatch is analysed with the line feed as shown in Fig.3 (a) and obtained bandwidth is $8.844 \%$, after that a triangular notch is introduced which is at upper-left position of the patch antenna as shown in Fig.3 (b) and obtained bandwidth is $9.003 \%$ and at last another triangular notch is introduced at the lower-right of the patch antenna as shown in Fig.3(c) and obtained bandwidth is $9.590 \%$.

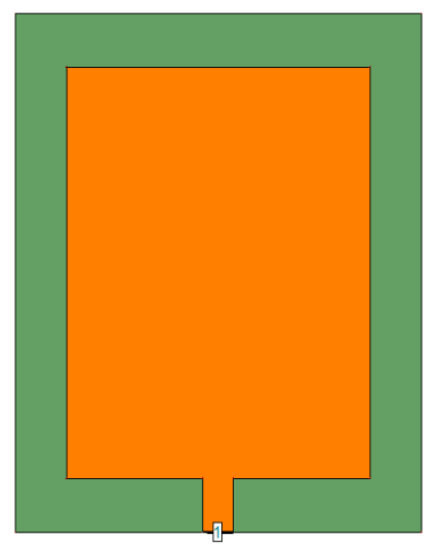

(a)

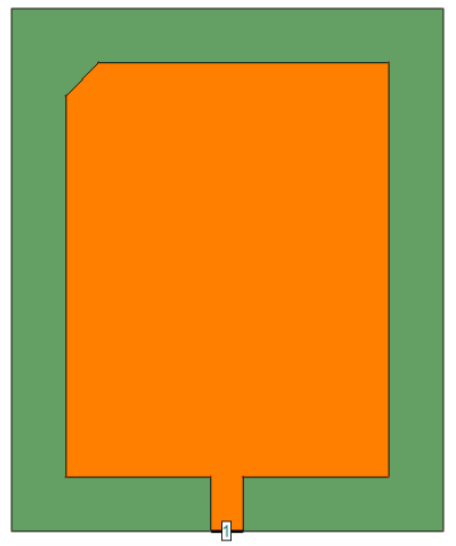

(b)

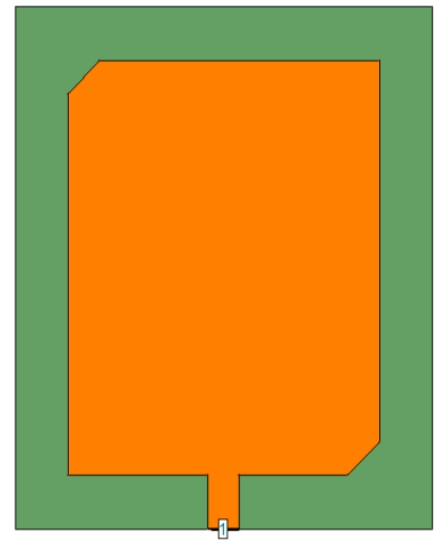

(c)

Fig.3 Antenna rayout with triangular notch (a) withouı ıuıching (b) with one notching (c) Wıu ıwo notching

\section{B. Effect of Rectangular notch}

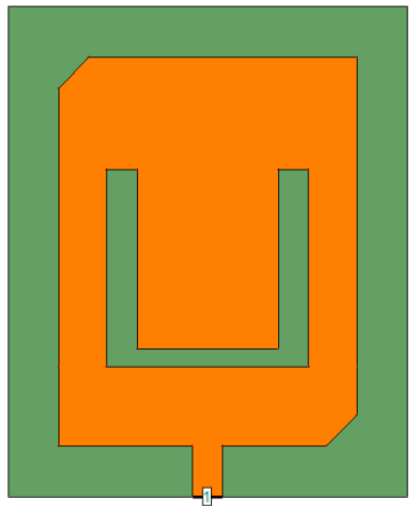

(a)

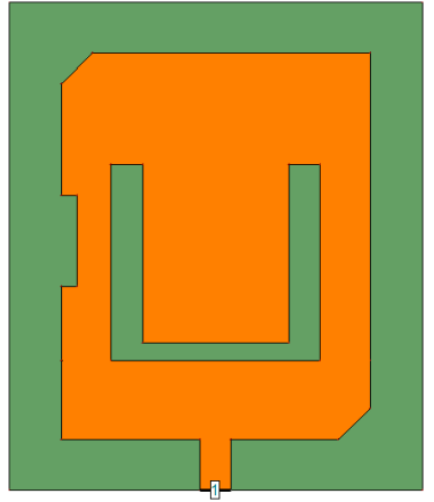

(b)

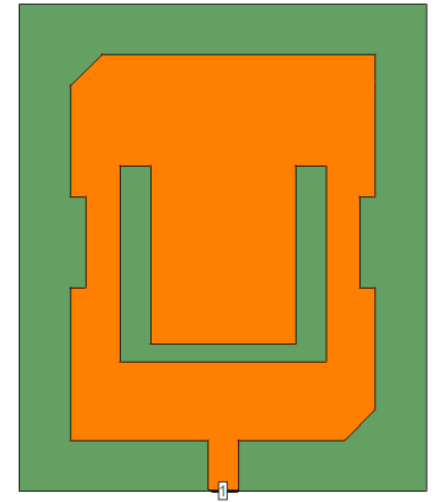

(c)

Fig.4 Antenna layout with rectangular notch (a) without notching (b) with one notching (c) with two notching 
Once the triangular notching is analysed, some of the parameters get improved. To obtain the optimum result some more variation is performed. Now a U shaped rectangular patch is analysed with the line feed as shown in Fig.4 (a), after that a rectangular notch is introduced at left side of the patch antenna as shown in Fig.4 (b) and at last another rectangular notch is introduced at the right side of the patch antenna as shown in Fig.4(c). Variation in the Resonant frequency, Return loss and Bandwidth are listed in Table 3 and their comparative simulated return loss of all design is shown in Fig.5.

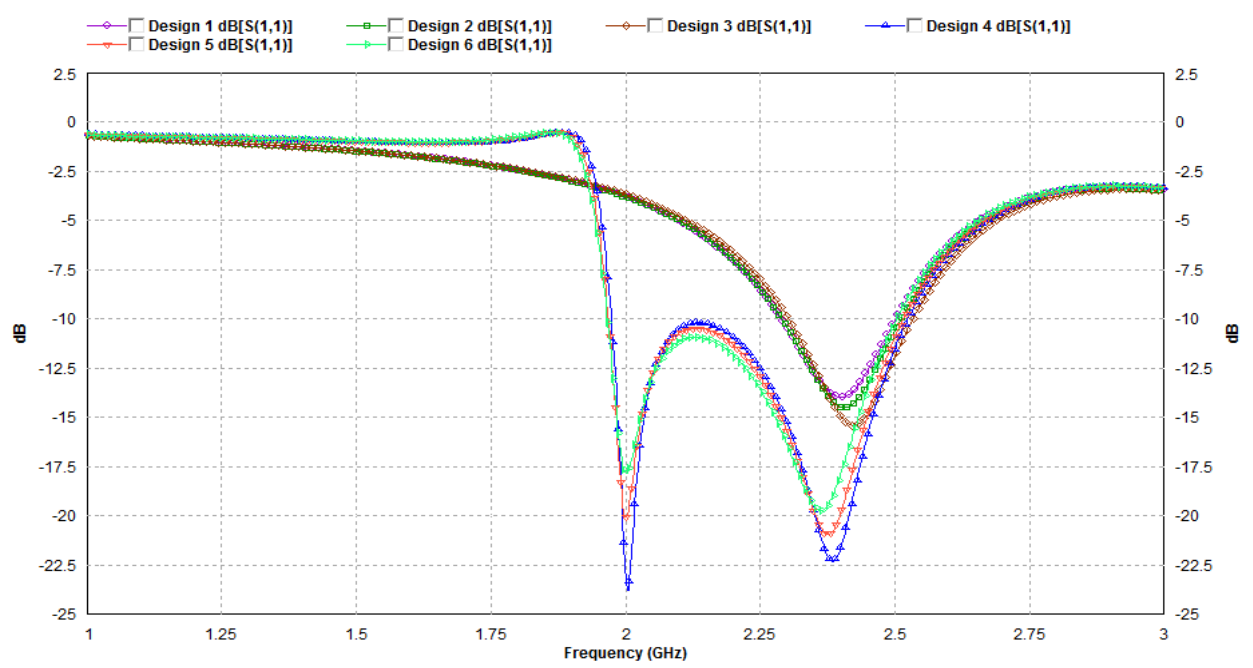

Fig.5 Representation of Return loss of different design of $U$ shape notched antenna

Fig.5 represent the variation of return loss of the different design of $U$ shape notched antenna and their resonant frequency, return loss, number of band and bandwidth are listed in table 3 as shown below.

Table 3: Result of the effect of the notching in the U shaped antenna

\begin{tabular}{|c|l|l|l|l|l|l|}
\hline Design & $\begin{array}{c}\text { No. of } \\
\text { Band }\end{array}$ & $\begin{array}{c}\text { Resonant } \\
\text { Frequency }(\mathbf{G H z})\end{array}$ & $\begin{array}{c}\text { Return } \\
\text { loss }(\mathbf{d B})\end{array}$ & $\begin{array}{c}\text { Lower } \\
\text { Frequency }(\mathbf{G H z})\end{array}$ & $\begin{array}{c}\text { Higher } \\
\text { Frequency }(\mathbf{G H z})\end{array}$ & $\begin{array}{c}\text { Bandwidth } \\
(\%)\end{array}$ \\
\hline Design1 & 1 & 2.403 & -13.88 & 2.291 & 2.503 & 8.844 \\
\hline Design2 & 1 & 2.403 & -14.33 & 2.291 & 2.507 & 9.003 \\
\hline Design3 & 1 & 2.423 & -15.55 & 2.303 & 2.535 & 9.590 \\
\hline Design4 & \multirow{2}{*}{2} & 2.002 & -23.25 & 1.970 & 2.114 & 7.051 \\
\cline { 2 - 7 } & 2.387 & -22.51 & 2.154 & 2.527 & 15.936 \\
\hline Design5 & \multirow{2}{*}{2} & 1.998 & -19.61 & 1.966 & 2.126 & 7.820 \\
\cline { 2 - 7 } & 2.387 & -20.94 & 2.130 & 2.519 & 16.734 \\
\hline Design 6 & 1 & 2.367 & -19.49 & 1.965 & 2.508 & 24.279 \\
\hline
\end{tabular}

Graph of Gain vs. Frequency of proposed antenna is shown in Fig.6.

Gain Vs. Frequency

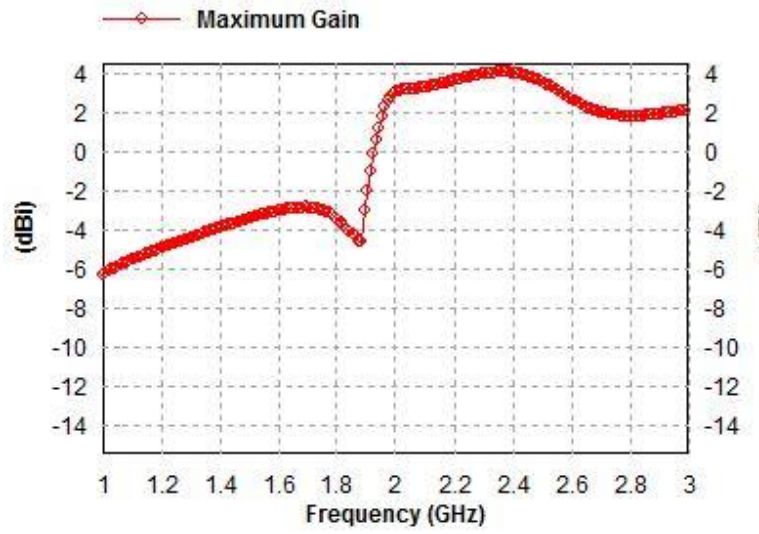

Fig.6 Gain vs. Frequency graph 
The Gain of proposed antenna at resonance frequency is $4.01543 \mathrm{dBi}$.

Graph of and Directivity vs. Frequency of proposed antenna is shown in Fig.7.

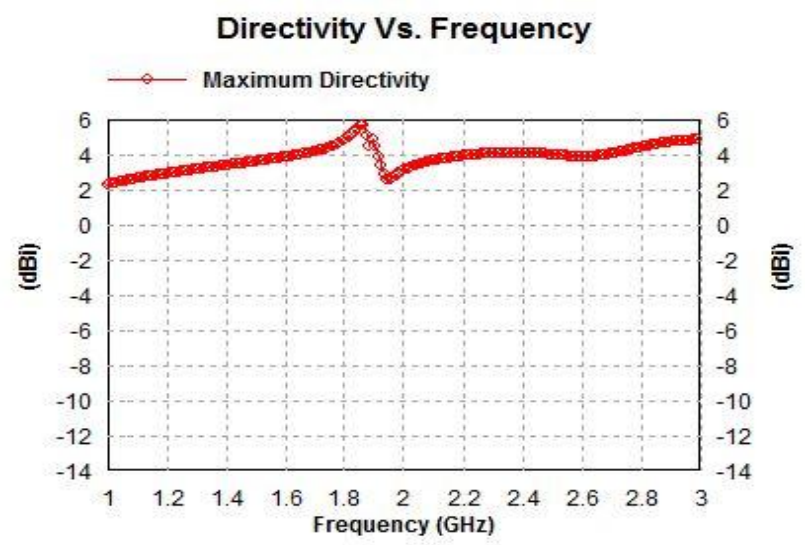

Fig.7 Directivity vs. Frequency graph

The directivity of proposed antenna at resonance frequency is $4.06451 \mathrm{dBi}$.

The graph of Efficiency of proposed antenna is shownin Fig.8.

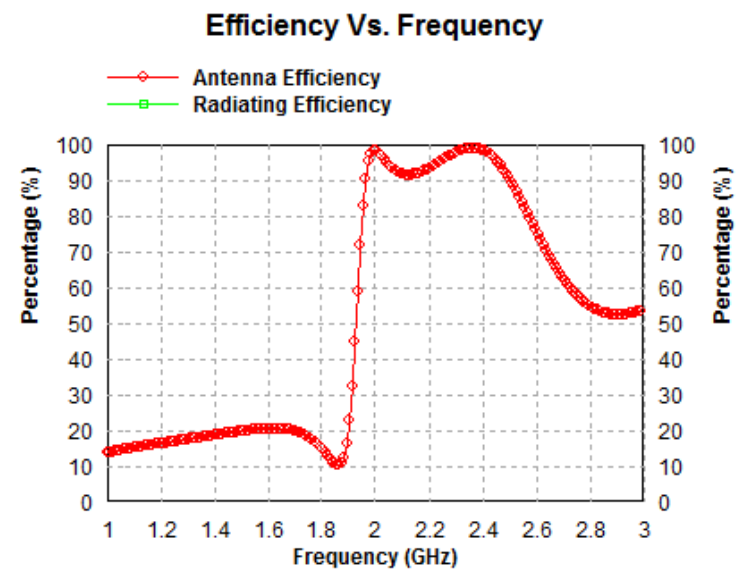

Fig.8 Efficiency vs. Frequency graph

It is calculated that the maximum antenna efficiency and radiation efficiency at resonant frequency of proposed antenna is $98.8763 \%$ and $99.8763 \%$ respectively.

The graph of $2 \mathrm{D}$ radiation pattern of proposed antenna is shownin Fig.9.

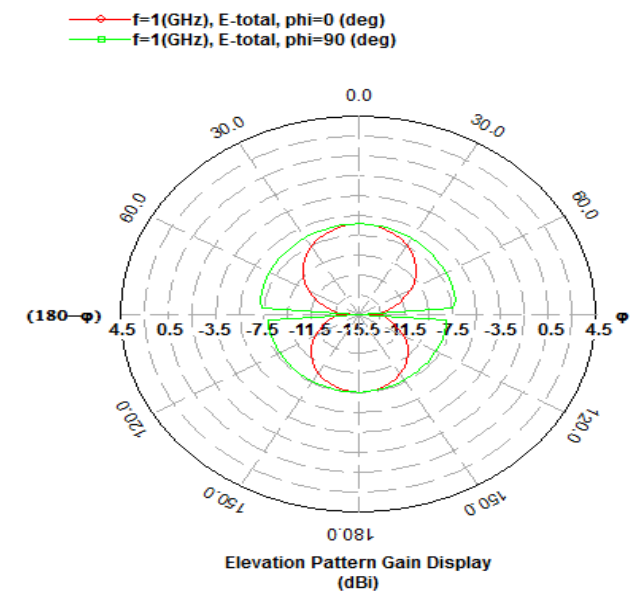

Fig.9 Radiation pattern 
The radiation pattern represents radiation of all power in two directions therefore it shows that the proposed antenna has bidirectional radiation pattern.

\section{CONCLUSION}

U shape notched microstrip patch antenna is proposed and analysed for the operation of Low frequency band (1.965 $2.508 \mathrm{GHz}$ ) at $2.367 \mathrm{GHz}$ resonant frequency and enhanced bandwidth is up to $24.279 \%$. The measured VSWR is about 1.237 is obtained at $2.367 \mathrm{GHz}$. Small variation is obtained between the operating frequency and design frequency of the proposed antenna. The design technique of the proposed antenna is used for the wireless Communication.

\section{REFERENCES}

[1] U. Chakraborty, "Compact Dual-Band Microstrip Antenna for IEEE 802.11a WLAN Application", IEEE Antenna and Wireless Propagation, vol. 13, pp. 407-410, 2014.

[2] Bahadir Yildirim, "Dielectric - Loaded Compact WLAN / WCDMA Antenna with shorted and Monopole Element.", IEEE Antenna and Wireless Propagation, vol. 12, pp. 288-291, 2013.

[3] Garg, R., Bhartia, P., Bahl, I., Ittipiboon, A., "Microstrip Radiators", Microstrip Antenna Design Handbook, Artech House, Inc, Boston, London, 2001.

[4] C. A. Balanis, “Antenna Theory: Analysis and Design”, John Wiley and Sons, INC., New York, Third Edition, 2005.

[5] Chih-Ching Chen, "Novel Compact Quad - Band Narrow strip-Loaded printed Monopole Antenna.", IEEE Antenna and Wireless Propagation, vol. 8, pp. 974-978, 2009.

[6] A.A Deshmukh and G. Kumar, "Compact broadband S-shaped microstrip antennas", Electronics Letters, vol. 42, no. 5, pp. 260 - $261,2006$.

[7] J. M. Patel, S. K. Patel and F. N. Thakkar, "Design of S-shaped multiband microstrip patch antenna,"2012 Nirma University International conference on Engineering (NUiCONE), Ahmedabad, pp.1-3, 2012.

[8] K. L. Wong and W. H. Hsu, "A Broadband Rectangular Patch Antenna with a Pair of wide slits",IEEE Transactions on Antennas \& Propagation, 49, pp. $1345-1347,2001$.

[9] Shuo Liu, Wen Wu, and Da-Gang Fang "Single-Feed Dual-Layer Dual-Band E-Shaped and U-Slot Patch Antenna for Wireless Communication Application" IEEE Antennas and Wireless Propogation Letters, Vol. 15, pp.468-471, 2016.

[10] X.M Yang, X. G Liu, Xiao Yang Zhou, and Tie Jun Cui, "Reduction of Mutual Coupling between Closely Packed Patch Antennas using Wave guided Metamaterials", IEEE Antennas and wireless propagation letters, Vol. 11, 2012.

[11] Mahrukh Khan, Deb Chatterjee, "Characteristic Mode Analysis of a Class of Empirical Design Techniques for Probe-Fed ,U-Slot Microstrip Patch Antennas",IEEE Transactions on Antennas and Propagation, vol. 64, pp.2758-2770, 2016. 